\title{
ON FRACTIONAL SMOOTHNESS OF FUNCTIONS RELATED TO $p$-VARIATION
}

\author{
MARTIN LIND
}

Abstract. This paper is concerned with the study of two functionals of variational type - the Riesz type generalized variation $v_{p, \alpha}(f)(1<p<\infty, 0 \leqslant \alpha \leqslant 1-1 / p)$ and the moduli of $p$ continuity $\omega_{1-1 / p}(f ; \delta)$. These functionals generate scales of spaces connecting the class $V_{p}$ of functions of bounded $p$-variation and the Sobolev space $W_{p}^{1}$. Some limiting relations in these scales are proved. Sharp estimates of $v_{p, \alpha}(f)$ in terms of $\omega_{1-1 / p}(f ; \delta)$ are obtained.

Mathematics subject classification (2010): Primary 26A45, secondary 46E35.

Keywords and phrases: Functions of bounded $p$-variation, generalized variations, optimal constants, function spaces.

\section{REFERENCES}

[1] V. A. AndRIEnKo, Necessary conditions for imbedding the function classes $H_{p}^{\omega}$, Mat. Sb. (N.S.) 78 (120) (1969), 280-300; English transl.: Math. USSR Sb. 7 (1969) No. 2, 273-292.

[2] J. Bourgain, H. BRÉZIS AND P. Mironescu, Another look at Sobolev spaces, Optimal Control and Partial Differential Equations. In honour of Professor Alain Bensoussan's 60th Birthday. J. L. Menaldi, E. Rofman, A. Sulem (eds), IOS Press, Amsterdam, 2001, 439-455.

[3] H. BRÉZIS, How to recognize constant functions. Connections with Sobolev spaces, (Russian) Uspekhi Mat. Nauk 57 (2002), no. 4(346), 59-74; English transl. in Russian Math. Surveys 57 (2002), no. 4, 693-708.

[4] R. A. DeVore And G. G. Lorentz, Constructive Approximation, Springer-Verlag, Berlin Heidelberg, 1993.

[5] G. H. HaRdy AND J. E. LitTlewood, Some properties of fractional integrals. I, Math. Z. 27 (1928), 565-606.

[6] V. I. Kolyada And M. Lind, On functions of bounded p-variation, J. Math. Anal. Appl. 356 (2009), no. 2, 582-604.

[7] A. Kufner And L. E. Persson, Weighted Inequalities of Hardy Type, World Scientific, 2003.

[8] M. Milman, Notes on limits of Sobolev spaces and the continuity of interpolation scales, Trans. Amer. Math. Soc. 357 (2005), no. 9, 3425-3442.

[9] I. P. NATAnson, Theory of functions of a real variable, Frederick Ungar Publishing Co., New York, 1955.

[10] K. I. OsKolkov, Approximation properties of integrable functions on sets of full measure, Mat. Sb. 103 (1977), 563-589; English transl. in Math. USSR Sb. 32 (1977), 489-514.

[11] J. Peetre, New thoughts on Besov spaces, Duke Univ. Math. Ser., Durham University Press, Durham, 1976.

[12] L. E. Persson, N. SAmKo ANd P. WAll, Quasi-monotone weight functions and their characteristics and applications, Math. Inequal. Appl., 15, 3 (2012), 685-705.

[13] A. P. TEREHIN, Approximation of functions of bounded p-variation, Izv. Vyssh. Uchebn. Zaved. Mat. (1965), no. 2, 171-187 (Russian).

[14] A. P. TEREHIN, Integral smoothness properties of periodic functions of bounded p-variation, Mat. Zametki 2 (1967), 289-300 (Russian).

[15] A. P. TEREHIN, Functions of bounded p-variation with a given modulus of continuity, Mat. Zametki 53 (1972), no. 6, 523-530; English transl. in Math. Notes, 12 (1972), 751-755 
[16] P. L. UL'YANOV, Imbeddings of certain function classes $H_{p}^{\omega}$, Izv. Akad. Nauk SSSR Ser. Mat. 32 (1968), 649-686; English transl. in Math. USSR Izv. 2 (1968).

[17] N. Wiener, The quadratic variation of a function and its Fourier coefficients, J. Math. Phys. 3 (1924), 72-94.

[18] L. C. Young, An inequality of the Hölder type, connected with Stieltjes integration, Acta Math. 67 (1936), 251-282. 